\title{
O corpo na escola: mapeamentos necessários ${ }^{1}$
}

\author{
Marisa Helena Silva Farah ${ }^{2}$ \\ Universidade de São Paulo, São Paulo-SP, Brasil
}

\begin{abstract}
Resumo: Este estudo propõe um mapeamento do corpo na escola, na tentativa de possibilitar aos educadores iniciantes uma construção do olhar para o aluno com seu corpo, bem como estimular o educador a se situar com seu corpo nesse contexto. Partindo da análise de dois eixos interdependentes: (1) a concepção de sujeito-corpo e (2) espaços e tempos do corpo na escola, busca-se contribuir para a discussão educacional, expondo como o currículo, a didática e a avaliação, entre outros elementos, podem sinalizar as considerações dadas ao corpo. O estudo conclui mostrando o parodoxo representado pelos mesmos elementos, quando problematizados por meio das relações de poder.
\end{abstract}

Palavras-chave: corpo, educação, currículo.

\section{The body within the school: necessary mappings}

\begin{abstract}
This paper proposes to map students' bodies in schools in the attempt to enable beginner educators to build a view of students with their bodies, and also to encourage educators to find their place in this context with their own bodies. The analysis of two interdependent axes: (1) concept of body-subject, and (2) space and time of the body in school, is expected to contribute to the educational discussion, by demonstrating how the curriculum, didactics, and evaluation, among other elements can signal considerations assigned to the body. The study concludes revealing the paradox represented by these same elements when defined by power relations.
\end{abstract}

Keywords: body, education, curriculum.

\section{El cuerpo en la escuela: mapeos necesarios}

\begin{abstract}
Resumen: Este estudio propone un mapeamento del cuerpo en la escuela en la tentativa de posibilitar a los educadores principiantes una construcción del ojar para el alumno con su cuerpo, bien como estimular el educador a se situar con su cuerpo en ese contexto. Partiendo del análisis de dos ejes interdependientes: (1) la concepción de sujeto-cuerpo y; (2) espacios y tiempos del cuerpo en la escuela; se busca contribuir para la discusión educacional exponiendo como el currículo, la didáctica, la evaluación entre otros elementos, pueden señalizar las consideraciones dadas al cuerpo y concluye mostrando la paradoja representada por los mismos elementos cuando problematizados por las relaciones de poder.
\end{abstract}

Palabras clave: cuerpo, educación, currículo.

É possível observarmos uma crescente demanda de estudos (teses, dissertações, livros e artigos), ofertas de cursos, formação de centros de estudos, cursos vivenciais, palestras e exposições sobre o tema corpo. A partir da década de 1990, o tema também ganhou destaque nos diversos trabalhos acadêmicos no campo educacional brasileiro, com diferentes tendências investigativas.

Nos trabalhos de Galvão (2004), Guerra (2005), Lima (1999), Mesomo (2004), Rocha (2001) e Vago (1999), identifica-se a tendência de pesquisa sobre o Corpo, escolarização e poder, na qual se investigam os temas: gênero, sexualidade, disciplinarização, higienização e controle, efetuando recortes dentro de uma determinada escola. Um

\footnotetext{
${ }^{1}$ Apoio: CAPES. Este trabalho é derivado das reflexões posteriores à dissertação de mestrado "Espaços e significados do corpo no Experimental da Lapa (1967-1972)" defendida pela autora no ano de 2005, sob a coordenação da Profa. Dra. Cecília Hanna Mate, no Programa de Pósgraduação da Faculdade de Educação da Universidade de São Paulo. Este texto foi revisado segundo Acordo Ortográfico da Língua Portuguesa (1990), em vigor a partir de $1^{\circ}$ de janeiro de 2009.

${ }^{2}$ Endereço para correspondência:

Marisa Helena Silva Farah. Rua Alarico Franco Caiubi, 71, Jaguaré, CEP 05.330-010. São Paulo-SP, Brasil. E-mail: marisafarah@ig.com.br
}

segundo tipo de investigação - Corpo, educação e currículo - representa as pesquisas realizadas nas áreas de Educação Física, Dança, Língua Portuguesa, Educação Musical, Educação Especial, Biologia e demais áreas, em uma perspectiva que se preocupa em inserir o corpo no currículo, como em Arnt (2005), Bundchen (2005), Cozzi (2004), Farah (2005), Fernandes (2004), Nunes (2001), Oliveira (2003), Santos (2003b), Souza (2004) e Tibúrcio (2005). A terceira tendência investigativa é Corpo e formação de professores na qual o enfoque encontra-se no corpo do professor, suas representações, percepções e as relações com a prática pedagógica, o que pode ser visto nos trabalhos de Angheben (2005), Bacri (2005), Chaves (2000), Cruz (2006), Dominick (2003), Duarte Junior (2000), Lucena (2004), Marinho (2005), Minello (2006), Nascimento (1999), Pederiva (2005), Santos (2003a), Silva (2004), Shimamoto (2004). Esses trabalhos não esgotam o tema, mas sinalizam caminhos para identificar algumas possíveis aparições e significações do corpo no campo educacional.

Apresenta-se a proposta de mapear o corpo na escola como pistas para questionamentos posteriores. Considerando a complexidade e amplitude do tema, entende-se que não há uma única maneira de apresentação, mas diversos caminhos, 
por meio de seus subtemas e dimensões nos quais se podem pesquisar, discutir e observar as questões pertinentes ao corpo na escola como: corpo e cultura, corpo e saúde, corpo e sexualidade, entre outros, resultando numa discussão vertical e pontual. Por outro lado, busca-se propiciar o desafio da multiplicidade de olhares sobre o corpo, dirigindo-se aos professores iniciantes que, entre outros desafios, estão sob dois domínios: aprender o ofício da docência e refletir sobre a sua ação.

Perrenoud (2002) identifica o professor iniciante sob diversos problemas que enfrenta ao começar a sua prática, destacamos alguns: a) ele se encontra na transição entre duas identidades, a de estudante e a profissional, b) demanda tempo para solucionar problemas que um professor experiente soluciona com mais facilidade, c) apresenta uma sobrecarga cognitiva para resolver tais problemas, d) oscila entre os modelos aprendidos na graduação e as "receitas sobre as práticas" que se constroem em diversas instituições escolares.

Se de um lado esse professor apresenta conflitos em administrar o tempo e a forma de preparação de seu trabalho, dificuldades em absorver a macroestrutura da dinâmica escolar em que se encontra e o domínio dos conhecimentos necessários para lidar com ela, por outro lado, suas condições são mais favoráveis à reflexão, pois inicia sua carreira enriquecido de ideias, atento às novas propostas e com uma maior disponibilidade para conhecer e perceber os fenômenos educacionais e as formas de educar que, no cotidiano do trabalho, o professor mais experiente já não percebe mais.

\section{Um mapa aberto}

O “conhecer" e o "perceber" tocam na seguinte questão: como realizar um estudo vertical de um fenômeno ou objeto sem considerar sua horizontalidade e vice-versa? Gallo (2006), numa perspectiva nietzschiniana, propõe novas formas de lidar com o conhecimento:

Para além de qualquer objetividade, para além de qualquer "vontade de verdade", é a multiplicidade de olhares sobre um mesmo objeto (isto é, um perspectivismo) que pode possibilitar-nos um conhecimento mais completo desse objeto (Gallo, 2006, p. 561).

Admite-se que, ao realizar um mapeamento, efetuamos um esquema de classificação, no entanto:

O mapa não reproduz um inconsciente fechado sobre ele mesmo, ele o constrói. (...) O mapa é aberto, é conectável em todas as suas dimensões, desmontável, reversível suscetível de receber modificações constantemente. Ele pode ser rasgado, revertido, adaptar-se a montagem de qualquer natureza, ser preparado por um indivíduo, um grupo, uma formação social (Deleuze \& Guatari, 2007, p. 22).
O mapeamento proposto para esta discussão se apresenta como uma metáfora, e, uma perspectiva pós-estruturalista que considera o significado como uma construção ativa e não universalista, com a intenção de localizar o corpo dentro dos elementos já presentes no campo educacional - currículo, projeto pedagógico, atividades extraclasse, entre outros, na certeza de que este, o corpo, não se prende a nenhuma categoria fixa. A realização de um mapeamento do corpo na escola - no qual pode emergir e qual sua função - se constitui numa construção contínua que pode e deve ser alterada, considerando os seguintes aspectos: a) o contexto político, social e econômico no qual o professor está inserido, b) as contínuas mudanças nas propostas educacionais, em seu aspecto teórico ou prático, c) as mudanças realizadas a partir das dinâmicas internas de cada unidade escolar, mediante observação dos espaços e tempos do cotidiano escolar, como também da prática pedagógica. Busca-se aumentar as possibilidades de sistematização de discussão sobre o tema para cada leitor, de acordo com suas próprias perspectivas, experiências e intencionalidades.

As provocações que se quer realizar apresentam-se como um conjunto de questões, na tentativa de dinamizar uma discussão sobre o tema, observando alguns dos espaços e tempos nos quais se pode investigar o corpo dentro da dinâmica escolar. Não é o propósito deste trabalho buscar uma resposta à pergunta: "qual é o lugar do corpo dentro da instituição escolar?”, mas possibilitar a sua visibilidade.

\section{O sujeito-corpo}

A primeira questão que se impõe ao tratarmos do tema "corpo", considerando-o em diferentes aspectos e dimensões, é a necessidade de aceitarmos a condição de que somos sujeitos-corpos, isto é, entendermos o corpo como nossa identidade, nossa unidade de existência que nos dá visibilidade e acesso ao mundo.

Está contida nessa concepção a ideia de que, em toda e qualquer ação que realizamos, é possível verificar três dimensões explícitas: biológica, psicológica e social, assim como dimensões implícitas, absolutamente interdependentes das anteriores: antropológicas, econômicas, históricas, entre outras.

Isso significa dizer que somos constituídos de estruturas e sistemas, ou seja, de uma anatomia: de ossos, articulações, órgãos, tecidos, de uma fisiologia: diversos sistemas do corpo como o sistema urinário, digestivo, cardíaco, sanguíneo, muscular, nervoso. A materialidade do corpo nos remete à sua própria temporalidade traduzida no nascimento, no crescimento, no amadurecimento, no adoecimento, no envelhecimento e na morte. De outro modo, significa também percebermos que é possível inferir sobre a constituição da psique por meio da constituição corpórea (anatômica), mas também da dinâmica corporal (os gestos, as posturas e as atitudes) que é o reflexo de nossas experiências em todas as fases da vida, num processo que se inicia desde a fase 
intrauterina, traduzindo assim os espaços internos e externos do corpo que nos dá visibilidade. Nessa direção implica considerar que "não há exterior sem interior e vice-versa" (Kignel, 2005, p. 52) e que "a percepção exterior e a percepção do corpo próprio variam conjuntamente porque elas são as duas faces do mesmo ato" (Merleau-Ponty, 1999, p. 276).

Nessa perspectiva, entendendo que somos seres sexuados, a dinâmica corporal se altera também de acordo com nossa libido, esse fenômeno energético não mensurável pulsão sexual caracterizada como um processo dinâmico que determina nossas atitudes e comportamentos como forma de aliviar a tensão sexual, que não se reduz ao genital. Mijolla (2005) aponta que Freud "até o fim de sua vida relacionará a teoria da libido com sua ancoragem corporal "(p. 1086), exemplificando no seguinte trecho de seu trabalho:

Não se pode discutir que a libido tenha fontes somáticas, que ela flua para o ego a partir de diversos órgãos e partes do corpo. As partes mais proeminentes do corpo de que esta libido se origina são conhecidas pelo nome de zonas erógenas, embora de fato, o corpo inteiro seja uma zona erógena desse tipo (Freud, 1996, p. 164).

A libido está diretamente relacionada com a afetividade, influenciando a dinâmica corporal e sendo influenciada na comunicação com o outro. Kignel (2005) evidencia a comunicação como "fazer contato, trocar substâncias" (p. 57) que não se resume pela palavra como um processo somente intelectual. Sendo o corpo nosso acesso ao relacionamento que se altera tanto na função receptiva quanto na expressiva, podemos dizer que estamos no outro e o outro está em nós, como resultado de um espelhamento entre o eu e o outro, traduzindo um jogo simbólico entre as imagens de um e de outro e definindo os papéis, de ambos, a serem desempenhados em um determinado contexto psicossocial.

Considera-se, também, o fato de que somos resultado de uma cultura, seja nacional, regional, comunitária, educacional familiar ou educacional escolar. Juntamente com as inscrições de uma determinada cultura, embora instáveis, inscrevem-se aí também as marcas ou os efeitos de determinados sistemas econômicos e políticos, que implicam diferentes relações dos corpos nos espaços geográficos e naqueles de domínio público e particular, em que somos assujeitados.

O corpo é também considerado como nossa identidade, porém transitória, o corpo enquanto estado, ou seja, como o corpo está e não o que o corpo é. De acordo com Katz e Greiner (2005), “como fluxo não estanca, o corpo vive no estado do sempre presente, o que impede a noção de corpo recipiente" (p. 130) diante das inúmeras transformações interdependentes que ocorrem em diferentes situações da vida, a cada informação que nos chega e nos transforma.

E, finalmente nos percebermos como corpos em movimento, o que significa considerar a existência de uma intencionalidade (ações em direção a algo que se deseja) e de uma motricidade que nos coloca em ação no mundo. Tais ações nos identificam como seres moventes.

Outras dimensões podem ser pensadas sobre o corpo e nenhuma delas o encerra, o define, o circunscreve. $\mathrm{O}$ corpo escapa a qualquer moldura, a qualquer circunferência e "não explica a si mesmo [...] não é um dado inequívoco, mas o efeito de uma elaboração social e cultural" (Le Breton, 2007, p. 26).

É sob essa perspectiva que pretendemos olhar os contornos da dinâmica da escolarização e identificar os sentidos dados ao corpo na escola, seja em seus espaços teóricos, metodológicos, epistemológicos, físicos, entre outros, assim como em seus tempos aos quais o aluno é submetido dentro da escola.

\section{Espaços e tempos do corpo na escola}

\section{Espaços teóricos, metodológicos, epistemológicos}

O primeiro espaço a ser considerado num mapeamento sobre o corpo na escola é o espaço do currículo que, conjugado ao projeto pedagógico da escola constitui a "medula" pela qual as concepções filosóficas de homem conectar-se-ão ao sentido todo da educação. Entende-se currículo como um projeto de educação o qual se constitui da seleção de experiências da cultura nacional, regional e educacional de cada unidade escolar e que se constrói juntamente com a seleção das habilidades, das atitudes e dos valores considerados necessários para viver em sociedade. A produção do currículo é realizada por pessoas que selecionam experiências e decidem as formas de aquisição de conhecimento, caracterizando este como um conjunto de saberes e discursos selecionados para responder como, o quê, por que e para quem se dirige tal proposta. Pessoas que falam de um determinado lugar (grupo social e econômico, gênero, cor, nacionalidade) e cujos discursos indicam sobre qual ideia de sujeito e sociedade se pretende formar no aluno.

O currículo se situa, assim, como o espaço do entrecruzamento entre saber e poder, constituindo-se, ele próprio, como um dos pontos centrais de reestruturações e reformas educacionais, desempenhando o papel de elemento discursivo da política educacional. A visão de mundo ali simbolizada, mesmo que não tenha efeito algum na dinâmica escolar (Silva, 1999), expõe os mecanismos de controle e regulação de determinados grupos sociais.

O fato de entendermos o currículo como elemento discursivo sob a temática do corpo implica considerar em primeiro lugar a formulação dos discursos e sua circulação.

Não há corpo que não esteja investido de sentidos e que não seja o corpo de um sujeito que se constitui por processos de subjetivação nos quais as instituições e suas práticas são fundamentais, assim como o modo pelo qual, ideologicamente, somos interpelados em sujeitos (Orlandi, 2001, p. 10). 
A proposta de análise do corpo no currículo sugere dois lugares para se olhar simultaneamente: a) examinar o conteúdo das propostas curriculares, ou seja, o que está de fato sendo proposto na materialidade da língua que possa considerar o corpo em sua afetividade, motricidade, expressividade, culturalidade e historicidade, b) identificar a forma como circulam as ideias ali expostas e observar o currículo oculto que se instala, isto é, a maneira como se transformam, se desviam e se deslocam as ideias, a partir dos sujeitos da educação em ação. Considerando o conteúdo e a circulação das ideias, propõe-se verificar no currículo a resistência à homogeneidade corporal, ou seja, como estão sendo consideradas as questões sobre as diferenças nas relações corpo e deficiência, no corpo e identidades, corpo: pele e moradia e corpo: bulliyng e violência.

\section{O corpo deficiente}

É possível discutirmos o corpo do deficiente dentro do espaço educacional não somente no espaço do currículo, mas também dentro das intenções de transformação do projeto pedagógico - considerando inclusive as necessárias adaptações no espaço físico da escola, verificando se, de fato, ocorre a acessibilidade da população de alunos com diferenças físicas, sensoriais e intelectuais, que até então vivenciaram a escolarização em instituições especializadas. O que é diferente no corpo do deficiente?

De acordo com Classificação Internacional de Funcionalidade, Incapacidade e Saúde (Organização Mundial da Saúde, 2003), as deficiências são entendidas como problemas nas funções (fisiológicas dos sistemas do corpo, incluindo as funções psicológicas) e problemas nas estruturas do corpo (partes anatômicas do corpo: órgãos, membros e seus componentes), caracterizando-se como um desvio significativo ou uma perda. Podem estar associadas a tarefas (limitações de atividade) e a dificuldades ou incapacidades de envolvimento em uma situação da vida (restrições de participação). Quais são as decorrências dessa diferença? Como estamos lidando com as diferenças corporais da pessoa deficiente?

As decorrências implicam primeiramente uma mudança de postura humana que se refletirá nas diversas ações e relações entre os sujeitos da escola, diante de um ambiente que se caracterizará por sujeitos com outros padrões motores, outras gestualidades, outras formas de comunicação e aprendizagem. Le Breton (2007) sinaliza o incômodo que acontece na comunicação com o sujeito-corpo diferente na qual "se finge" que as alterações corporais e sensoriais ali expostas não criam nenhuma diferença, nenhum mal-estar quando ficamos impossibilitados de identificação com o outro. Isso implica questionarmos: Quais formas de aproximação com essas pessoas estão sendo propiciadas pela escola para que alunos, pais, professores e demais agentes da escola possam facilitar suas vidas? Como ocorre a preparação do professorado para lidar com essa situação pedagógica que impõe um maior preparo cognitivo, psicológico e físico do professor, como também uma ação multidisciplinar que requer profissionais de outras áreas atuando conjuntamente dentro da escola? Quais os formatos da inclusão em cada escola? Há dispositivos pedagógicos de fato para que a construção do conhecimento ocorra? Quais são as políticas públicas educacionais que permitem uma melhor estruturação da escola?

O currículo, ao focalizar as diferenças, aponta duas iniciativas fundamentais: a) a aceitação das diferenças, compreendendo inclusive a origem destas e b) a proposição de um diálogo (Moreira, 2002). Que tipo de diálogo pode-se propor sem antes constatar os diferentes sujeitos-corpos que somos (cheiros, cores, formatos, gestuais, padrões motores, sexualidades) e aceitarmos um diálogo com esses sujeitos que têm outros modos de aprender, de se relacionar e de se comunicar por meio de outros sistemas: Sistema Braille, Língua de Brasileira de Sinais - LIBRAS; e outros modos de estar e transitar no mundo: cadeira de rodas, muletas, andadores, mas também com seus modos de compreender o mundo?

\section{O corpo e as identidades}

Ao trabalhar no campo das diferenças, aproximamo-nos dos conceitos de gênero, identidade e sexualidade, que juntos se constituem em uma complexa relação de interdependência como também locus de forças e relações de poder, considerando inclusive as novas transformações ou construções corporais que se realizam na sociedade contemporânea e nas diversas possibilidades identitárias que se constroem a partir destas.

Parte-se da perspectiva de que somos constituídos como homens e mulheres pelas diversas instituições e práticas sociais, frutos das diversas formas de educação e dos processos que a envolvem em cada período histórico, bem como dos lugares e das circunstâncias em que vivemos. Encaminhase, então, uma pergunta: Quais são as práticas, os discursos instituídos e a cultura vivenciada sobre o que é ser homem ou ser mulher, ser menino ou ser menina em uma determinada escola?

Podemos verificar as relações de poder que esses conceitos traduzem dentro da educação no exemplo que Silva (2001) nos apresenta. Segundo esse autor, a produção teórica brasileira no campo educacional foi historicamente construída por homens e a docência por mulheres "o pensamento educacional brasileiro é inflexivelmente machista e patriarcal. Paradoxalmente, a docência e magistério de $1^{\circ}$ e $2^{\circ}$ graus é predominantemente feminina" (p. 32).

Quais experiências femininas estão sendo excluídas desse currículo? Por outro lado, no que se constituem experiências do feminino e do masculino? Em qual sociedade e comunidade? Ou que implicações afetivas, cognitivas e motoras ocorrem com os(as) alunos(as), diante de um quadro docente predominantemente feminino ou masculino?

Oliveira (2007) aponta os novos contornos e dimensões plurais de gênero - masculinidades e feminilidades dentro da docência que sinalizam rupturas do binarismo relacionadas a gênero e sexo - homem/mulher e configuram novas 
construções identitárias. Outras construções binárias podem ser examinadas dentro do campo educacional para questionarmos o corpo na escola: corpo/mente, motor/cognitivo, cultura/natureza.

Dentro do espaço das masculinidades e feminilidades, articula-se a discussão da sexualidade na escola. Quais são os espaços de orientação, informação e discussão para uma educação sexual na escola?

Historicamente o assunto da sexualidade tem sido tratado na escola como Educação Sexual tendo como base as áreas da Biologia e da Saúde, abordado mais correntemente nas aulas de Ciências e incidindo mais sobre a funcionalidade do sistema reprodutor do que sobre o sistema sexual. As orientações seguem em direção de prevenções da gravidez precoce e doenças sexualmente transmissíveis e não do prazer corporal.

Embora esses fatos acusem nossa realidade, chama-se atenção para as bases da higienização e saúde, contidas nessa proposta, que se aproxima da relação corpo- disciplinarização e com isso se distancia da discussão corpo-prazer que a tornaria mais complexa, pois implicaria considerar as masculinidades e feminilidades possíveis dentro dos conceitos de gênero, sexualidade e identidade.

Louro (2007) identifica a diversidade de conceptualizações sobre a sexualidade, mostrando que o determinismo biológico ainda se mantém como referência forte para algumas teorias sobre a sexualidade e desconsiderando que a sexualidade implica mais do que a constituição biológica, pois estão envolvidos os valores, as linguagens, as fantasias, as representações que expressam desejos e prazeres.

De acordo com Oliveira (2007), "o desafio é romper o esquema binário em que masculino e feminino se constroem na oposição [...] e rejeitar o caráter fixo e permanente dessa oposição em termos de diferença sexual, dando visibilidade aos sujeitos diferentes" (p. 50).

Nessa direção decorrem algumas questões: O que ocorre nas relações interpessoais entre alunos(as) e professores(as) e entre o corpo docente da escola diante da presença de um professor/aluno gay ou de uma professora/aluna lésbica? Como esses sujeitos têm permanecido na escola? Quais seriam suas formas de resistência?

\section{O corpo: pele e moradia}

Quais seriam as implicações decorrentes das relações interpessoais entre sujeitos professores e alunos, diante da diferenciação da cor da pele e do tipo de cabelo da população negra e da moradia dos sujeitos?

Gomes (2003), em um estudo que relaciona educação, identidade e a formação de professores, sugere alguns questionamentos que parecem pertinentes para essa discussão. A particularidade do cabelo crespo aparece nesse trabalho como destaque e símbolo identitário da cultura afro-brasileira e mostra as múltiplas formas de modificação estética realizada pelos negros e o controle dessa estética para que a aceitação da população negra ocorra. Sugerimos algumas questões: a) o que impede a aceitação das diferenças da cor de cabelo e da cor da pele dentro de uma escola? b) quanto a população negra tem realizado transformações no cabelo para aproximar-se de uma estética mais aceita? c) qual seria a estética aceita ou estabelecida para os negros numa determinada escola? d) quantas escolas já inseriram a História da Cultura Afro-brasileira (Lei 10.639 de 9 de janeiro de 2003) e como a prática pedagógica se exerce possibilitando o encontro com as questões étnico-raciais? e) qual população predomina numa escola, negros, brancos, pardos? f) quais são as trocas afetivas e as possibilidades de aproximação física que a Educação Física, a Dança e o Teatro da escola promovem? g) qual é a reação dos alunos diante de um(a) professor(a) negro(a) numa determinada escola?

As diferenças nos corpos podem ser ainda tratadas na articulação entre a origem dos sujeitos da escola, o espaço da moradia, sua localização político-geográfica e as condições socioeconômicas em que se vive. Santos (2004) entende o espaço como "um conjunto indissociável, solidário e também contraditório de sistemas de objetos e sistemas de ações, não considerados isoladamente, mas como quadro único no qual a história se dá" (p.63).

A ambiência do espaço em que se vive - estética, higiênica, afetiva e social - pode influenciar a noção de identidade e subjetividade. Tavares e Albertini (2005) sinalizam as "vivências de instabilidade no corpo e no espaço, experimentadas pelos moradores de favela" (p. 2), considerando que a noção de subjetividade implica corporeidade. Os objetos de arte criados por Lygia Clark em $1968 O$ corpo é a casa e $A$ casa é o corpo nos convidam a pensar primeiramente o corpo como primeira morada, isto é, o corpo como casa, identidade, espaço pessoal, mas simultaneamente a casa, a moradia como o cenário onde se constroem as recordações "que são rastros, indícios pistas em nossa memória (erinnerunpuren) que se vão transformando em um espaço encorporado (embodied), ou de incorporação (verköperung), personificação do corpo próprio" (Valadares, 2000, p. 86).

Para esse lugar onde podemos olhar o corpo, seguem as seguintes perguntas: a) quais são os locais de moradia dos sujeitos da escola e as inscrições que habitam seus corpos? b) que cheiros, formatos, gestualidades e maneiras de falar e vestir caracterizam esses sujeitos? c) quais usos e significados eles fazem do corpo?

\section{Corpo: bullying e violência}

Dentro do círculo educacional, é o termo bullying que vem se disseminando e dando contorno às questões de todo tipo de intimidação física e verbal com significativo desnível de poder exercido sobre o outro: chutar, espancar, socar, implicar, insultar, intimidar, excluir. Ele se insere no grande quadro polissêmico da violência a qual designa vários tipos de comportamentos de causas distintas: agressão física, extorsão, vandalismo, incivilidade (xingamentos, linguagem rude, humilhação), intimidação, depredação das instituições (Debarbieux, 2002). Deve-se, considerar, também que as 
diferentes formas de violência -considerando homicídios e estupros - já chegaram às escolas tanto públicas quanto privadas.

O estudo de Fante (2005) indica que o fenômeno do bullying é tão antigo quanto a própria escola, podendo por isso ser considerado no "discurso educacional", de alguns sujeitos da escola, como uma cultura instalada entre grupos dominantes e dominados, "fazendo parte da vida". A autora identifica o surgimento da Síndrome de Maus-Tratos Repetitivos (SMAR), dentro da escola, como resultante das ações sofridas pelas vítimas que desenvolvem, entre outros, doenças psicossomáticas, psicopatologias graves, sintomatologias de estresse e transtornos mentais. Fante (2005) e Smith (2002) apontam que frequentemente essa intimidação é o resultado da não aceitação de algum tipo de diferença:

seja ela qual for, mas sempre notória e abrangente, envolvendo religião, raça, estatura física, peso, cor dos cabelos, deficiências visuais, auditivas e vocais; ou é uma diferença de ordem psicológica, social, sexual e física; ou está relacionada a aspectos de força, coragem e habilidades desportivas e intelectuais (Fante, 2005, p. 62).

Agressor e vítima podem ser observados pelo viés da afetividade que se constrói no corpo, desde os primeiros meses de vida. De que maneira o agressor e a vítima vivenciaram a afetividade em suas vidas e como foi sendo reproduzida na relação com o corpo do outro? Quais apelos de um corpo ali representado num "espetáculo de horror" podem estar se fazendo visíveis? Com quem, onde, como e por que essa intimidação pode estar ocorrendo dentro da escola? Em qual faixa etária? Quais estratégias de ação estão contidas no Projeto Pedagógico, se é que ele de fato funciona como dispositivo de diagnóstico do contexto interno e externo da escola, para tratar dessa questão?

\section{Corpo e conhecimento}

Considerando ainda a dimensão curricular, podemos tentar identificar as considerações dadas ao corpo em outras instâncias. Primeiramente verificar a presença, o conteúdo e a tendência filosófica das disciplinas (ex: Dança, Educação Física-EF, Teatro) ou atividades que por suas características contemplam o corpo direta ou indiretamente, bem como aquelas cujas ações pedagógicas do professor dirigem-se a um trabalho interdisciplinar. Em um segundo momento, identificar o uso, ou não, dos livros didáticos- $L D$, e as imagens e modelos dos corpos que ali estão representados sob o conteúdo das diversas disciplinas e como estão sendo abordadas as questões de gênero, etnia e sexualidade.

Em um terceiro momento, relacionarmos corpo e avaliação. Paradoxalmente esta relação nos leva a refletir acerca dos conceitos sobre conhecimento, cognição e inteligência. Tanto a avaliação que é dinâmica quanto a "examinação" que é sempre pontual têm como objetivos verificar se um determinado conteúdo foi apreendido pelos alunos, dentro do campo legitimado de conhecimentos, bem como de classificá-los excluindo outros - alunos e conhecimentos. Nessa perspectiva algumas áreas do conhecimento parecem não estar inscritas como importantes na formação dos sujeitos, principalmente Artes, EF, Dança, Teatro, na medida em que, se por um lado não há uma preocupação com a "examinação" -dar notas - nessas disciplinas, por outro, o conhecimento que se adquire ali não tem visibilidade na valoração geral do conhecimento escolar. Não há intenção de provocar o aparecimento de práticas examinatórias, mas questionar: Quais disciplinas de fato valem na lógica educacional? Como bem apontou Nóbrega (2005) é a uma "razão sem corpo" que temos privilegiado na educação.

Os estudos de Varela, Thompson e Rosch (2003) e de Merleau-Ponty (1999) se complementam e trazem o corpo na relação cognição-percepção, conhecer-perceber. Para Merleau-Ponty, é o próprio corpo o sujeito da percepção que se caracteriza como experiência que se efetua dentro de um só ato: a experiência possibilita perceber o mundo e a si mesmo simultaneamente. Para Varela e cols. (2003), a enação (processos cognitivos que emergem dos processos vitais) evidencia que o "conhecer" é incorporado por meio de uma diversidade de processos que traduzem as nossas possibilidades sensório-motoras. Esses conceitos nos encaminham a realçar a motricidade humana como a dimensão do corpo que dá, mediante a experiência, o sentido da vida. Qual pedagogia é privilegiada na escola?

Gaia (2006) sugere três instâncias de investigação do corpo para a transformação de uma pedagogia que se inscreva como uma pedagogia da complexidade: a passividade do corpo na escola; a ausência de interesse epistemológico do corpo nas principais correntes sobre o conhecimento e a permanência de uma pedagogia racional. Para o autor, "o corpo não vai à escola" (p. 251) no sentido de que as considerações dadas ao corpo incidem mais na disciplinarização dos corpos do que nas experiências lúdicas e expressivas.

A que/quem a existência das disciplinas citadas acima estariam respondendo dentro das propostas educacionais? O professor se reconhece como sujeito-corpo na relação com os alunos?

\section{Os tempos e os espaços físicos para o corpo movente}

Corpo faz par com motricidade em uma relação que não se desfaz a não ser na morte. A condição humana de ter acesso ao mundo é uma condição de ação, e sempre essa ação é motora, independentemente do grau de complexidade e das partes do corpo envolvidas. Retomemos as disciplinas que tratam direta ou indiretamente do corpo em movimento: EF, Esporte, Dança e Teatro, para dar visibilidade à motricidade inerente às suas práticas. Com enfoques e objetos de estudo diferentes, elas constituem o locus no qual o movimento é um fator fundante, mas ainda não considerado relevante 
suficientemente dentro da educação. Veremos onde e como isso pode ser observado.

Um elemento que tem se apresentado sob diversos formatos na escola é a Atividade Extraclasse (AEC). Atualmente o termo vem sendo utilizado com diferentes significados, tanto no ensino público como no privado, como também para as atividades do professor e para as atividades do aluno. Entende-se por AEC as ações necessárias e programadas dentro de um determinado currículo, projeto pedagógico, seleção de determinados conteúdos, assim como das didáticas em que se inserem, da qual fazem parte os passeios, as visitações às empresas, museus, fábricas, jornais, como também as viagens e as saídas próximas à escola para locais específicos que demandem o estudo do meio. Essa concepção não nega nem se distancia das possibilidades de entretenimento e das estreitas relações com os eventos culturais que a própria atividade busca, mas se afasta da ideia de AEC como opção de lazer aos alunos por si só, pois na perspectiva corporal que se propõe aqui, tais atividades podem se encaixar tanto nos espaços teóricos e metodológicos como nos fatores do espaço físico para um corpo que se move.

A existência ou não de AEC pode nos fazer observar as possíveis experiências com os fatores tempo e espaço, quando propomos aos alunos a saída da sala de aula e da escola. $\mathrm{O}$ que ocorre em nossas ações corporais - professores(as) e alunos(as) - quando vamos ao encontro do conhecimento em outros espaços? De que maneira vivenciamos o tempo de ida e volta e da atividade em si? Quais tipos de experiências sensoriais, motoras, afetivas e sociais nossos corpos podem experimentar no trajeto, se vamos a pé ou de ônibus? Quais sensações corpóreas nos ocorrem ao visitar uma caverna diante de sua ambiência -luminosidade, temperatura, cor, cheiro ou ao visitar cidades cuja geografia é irregular - subir, descer, equilibrar-se, cansar, descansar?

O segundo elemento para considerarmos a motricidade é a arquitetura da escola. Tenta-se investigar quais foram os critérios de escolha na construção do espaço físico escolar, como os elementos desse espaço estão distribuídos e o que estes propiciam aos alunos e agentes da escola em termos de: deslocamentos, formas de controle e vigilância dos alunos, situações de ensino, sentimentos relativos à ambiência, adequação dos materiais e objetos de manipulação e experiências motoras e sensoriais?

Nessa direção, propõe-se, então observar a existência ou não das salas ambiente, quadras, ginásio, teatro, parquinhos, cantinhos, espaços com árvores, plantas e flores, hortas e as condições de tais espaços, considerados específicos ao trabalho corporal, no qual podemos observar as condições de uso do piso, a ventilação, a cobertura da quadra no caso de mudanças climáticas, bem como considerar a existência dos espaços e tempos para a higiene dos alunos e o procedimento de manutenção da limpeza e dos recursos materiais desses espaços.

Quanto aos materiais pedagógicos para a área motora - colchonetes, cordas, bolas - podemos verificar a sua existência e as condições de seu armazenamento e conservação.
O desenvolvimento da escrita não ocorre sem ao menos a existência de um lápis para cada aluno. No caso da motricidade geral, dificilmente encontramos o material individual para cada aluno. Que interesse a motricidade desperta em diretores, coordenadores e professores? Estaria contemplada no currículo? Qual cultura corporal de movimento subsidia a prática de ensino da Educação Física Escolar?

Ao considerarmos a natureza motora dos sujeitos, a integração entre mobília da sala de aula e a anatomia do corpo humano pode não estar ocorrendo, pois mesas e cadeiras podem ser inadequadas e desconfortáveis ao tamanho das crianças e dos alunos e dispostas no espaço sem possibilitar a circulação e o agrupamento dos alunos. Como a escola lida com essa relação?

Mantendo a perspectiva da motricidade questionamos: Qual é o espaço e o tempo destinados para o recreio, considerando as faixas etárias dos alunos, e quais atividades são permitidas nestes? Para que serve o recreio? Defendemos a ideia de que o recreio se constitui como o único momento em que não deveria haver uma proposta diretiva, para que crianças e alunos possam construir suas próprias hipóteses de movimento, de brincadeira, de agrupamentos entre si, de uso de materiais.

Outro elemento relevante nesse mapeamento é a inquietação corpórea dos alunos. Observados em aulas expositivas, os alunos não cessam de buscar ora uma posição mais confortável, ora um deslocamento nesse espaço. A inquietação corpórea pode nos indicar que o tempo de atenção dos alunos é inversamente proporcional à sua necessidade de movimentação. Podemos indagar: Quais seriam as modalidades didáticas utilizadas pelo professor? Quanto tempo é possível permanecer sentado e atento a uma aula expositiva? Será que a "indisciplina" dos alunos de uma escola está pautada na quietude de seus corpos?

Aquino (2003) aponta que a indisciplina tem sido tratada dentro da escola por dois ângulos: o sociológico e o psicológico. As causas dos "indisciplinados" podem ser apontadas nas contextualizações exteriores à escola, sendo esta como reprodutora dessa exterioridade - família e sociedade ou, as causas podem ser de fundo psicológico em que os "indisciplinados", após serem diagnosticados, seriam "encaminhados" para os profissionais “psi” (psicopedagogos, psicólogos, psicomotricistas, psiquiatras), isentando totalmente a parcela da própria escola como geradora da indisciplina. O que é significativo das reflexões desse autor é que, embora estabeleça relações da indisciplina com as atitudes do professor, mostra uma exceção testemunhada pelos professores de Educação Física e Artes quanto ao número menor de "infrações disciplinares" dos alunos. O que é considerado indisciplina em cada unidade escolar e em qual faixa etária? A indisciplina pode estar associada, muitas vezes, a determinados discursos do professorado, ao que se refere à inquietação corpórea dos alunos e à sua necessidade de movimentação. Que tipo de relação se estabelece entre professor e aluno diante das normas de controle dos corpos na sala de aula? 
Por fim, propõe-se observar a regularidade de tempo planejada para as aulas das disciplinas já citadas, que podem sinalizar, entre outras, as funções que estas exercem na escolarização e na educação como um todo, considerando suas trajetórias históricas na unidade escolar investigada, e nessa perspectiva os papéis desempenhados por seus professores e seu poder de representação na escola. Tentar entender, em outras palavras: Essas disciplinas estão ali para quê? Há uma preocupação de fato com o ensino de Arte ou com a motricidade dos alunos?

\section{Considerações finais}

Partindo de dois eixos interdependentes: sujeito-corpo e espaços e tempos do corpo na escola e considerando que a construção de um mapeamento é sempre aberta, o trabalho limitou-se a dar visibilidade ao corpo no currículo, no projeto pedagógico, na didática entre outros, envolvidos na heterogeneidade corporal (gênero, sexualidade, etnia e deficiências), na relação com o conhecimento (disciplinas, conteúdos, LD, avaliação) e na motricidade (práticas, materiais, arquitetura, tempo, entre outros). No entanto, ao investigar $o$ que, onde, como e quando o corpo é considerado na escola, verifica-se que foi por intermédio desses mesmos elementos que, em nome de uma sociedade mais moderna e racional, pudemos identificar na história da escola, inclusive a brasileira, as inúmeras formas de disciplinarização, controle e higienização dos corpos dos alunos. Como e por que tais elementos aparecem e desaparecem e sob qual tipo de controle e governo são orientados? Michel Foucault (1987) chamou de "fábricas de ordem" as instituições disciplinares constituídas a partir do século XVIII como o exército, o hospital, a prisão, a fábrica e a escola. Quais seriam as práticas corporais disciplinadoras (fila, controle dos gestos, comportamentos, discursos, técnicas corporais, novas disciplinas) e seus efeitos nos corpos que as instituições escolares realizam no intuito de manter a ordem e simultaneamente formar alunos para servirem a um tipo de sociedade? Estaríamos ainda numa sociedade-escola disciplinar com seus princípios coercitivos ou, numa sociedade-escola de controle na qual o princípio da sedução é o dispositivo que rege os corpos? Ou, ambas, simultaneamente? Uma última pergunta aos leitores: como crianças e adolescentes, alunos que fomos, qual seria, então, nossa história de corpo e de movimento que influenciou, desarticulou e encantou agora como educadores as nossas atuais práticas pedagógicas?

\section{Referências}

Angheben, V. L. Z. (2005). A ginástica rítmica na corporeidade dos acadêmicos de educação física: Relações entre o pensar, o falar e agir com o corpo. Dissertação de mestrado não publicada, Universidade Federal do Rio Grande do Sul, Porto Alegre.
Arnt, A. M. (2005). De muros, tempos artes e pingue-pongues dos genes, anfioxos, mórulas e trissomias: Falando do corpo nas práticas escolares. Dissertação de mestrado não publicada, Universidade Federal do Rio Grande do Sul, Porto Alegre.

Aquino, J. G. (2003). Indisciplina: O contraponto das escolas democráticas. São Paulo: Moderna.

Bacri, A. P. R. (2005.) Influência dos bloqueios corporais na educação. Dissertação de mestrado não publicada, Universidade Federal de Uberlândia, Uberlândia, MG.

Bundchen, D. B. S. (2005). A relação ritmo-movimento no fazer musical criativo: Uma abordagem construtivista na prática do canto coral. Dissertação de mestrado não publicada, Universidade Federal do Rio Grande do Sul, Porto Alegre, RS.

Chaves, S. N. (2000). A construção coletiva de uma prática de formação de professores de Ciências. Tese de doutorado não publicada, Universidade Estadual de Campinas, Campinas, SP.

Cozzi, T. de R. (2004). Na passarela de uma escola: A evolução da linguagem escrita ao ritmo da fala e do corpo. Dissertação mestrado não publicada, Universidade Federal Fluminense, Niterói, RJ.

Cruz, M. C. M. (2006). Para uma educação da sensibilidade: A experiencia da Casa Redonda: Centro de Estudos. Dissertação de mestrado não publicada, Universidade de São Paulo, São Paulo.

Debardieux, E., \& Blaya, C. (Orgs). (2002). Violência nas escolas e políticas públicas (P. Zimbres, Trad.). Brasília: UNESCO. (Original publicado em 2002)

Deleuze, G., \& Guatari, F. (2007). Mil platôs: Capitalismo e esquizofrenia (A. Guerra Neto \& C. P. Costa, Trads.). São Paulo: Editora 34. (Original publicado em 1980)

Dominick, R. S. (2003). Imagens, memórias vividas e compartilhadas na formação docente: Os fios, os cacos e a corporificação dos saberes. Tese de doutorado não publicada, Universidade Estadual de Campinas, Campinas, SP.

Duarte-Junior, J. F. (2000). O sentido dos sentidos: $A$ educação do sensivel. Tese de doutorado não publicada, Universidade Estadual de Campinas, Campinas, SP.

Fante, C. (2005). Fenômeno bullying: Como prevenir a violência nas escolas e educar para a paz (2a ed.). Campinas, SP: Versus Editora.

Farah, M. H. S. (2005). Espaços e significados do corpo no "Experimental da Lapa (1967-1972)". Dissertação de mestrado não publicada, Universidade de São Paulo, São Paulo.

Fernandes, T. da C. (2004). Educação sensibilidade: A ética e a estética da corporeidade no currículo. Tese de doutorado não publicada, Universidade de São Paulo, São Paulo.

Foucault, M. (1987). Vigiar e punir: História da violência nas prisões (R. Ramalhete, Trad.). Petrópolis, RJ: Vozes. (Original publicado em 1975) 
Freud, S. (1996). A teoria dos instintos. In: S. Freud, Obras psicológicas completas de Sigmund Freud (Vol. 23, pp.161-164). Rio de Janeiro: Imago. (Original publicado em 1949)

Gaia, A. (2006). A reinvenção dos corpos: Por uma pedagogia da complexidade. Sociologias, 15, 250-272. Recuperado em 10 abril 2009, de http://www.scielo.br/pdf/soc/n15/ a09v8n15.pdf

Galvão, E. F. C. (2004). A produção da corporalidade na escola: Uma análise do projeto da Educação de jovens e adultos em Angra dos Reis. Tese de doutorado não publicada, Universidade Federal Fluminense, Niterói, RJ.

Gallo, S. (2006). Modernidade/pós-modernidade: Tensões e repercussões na produção de conhecimento em educação. Educação e Pesquisa, 32, 551-565.

Gomes, N. (2003). Educação, identidade negra e formação de professores/as: Um olhar sobre o corpo negro e o cabelo crespo. Educação e Pesquisa, 29, 167-182.

Guerra, J. (2005). Dos segredos sagrados: Gênero e Sexualidade de uma escola infantil. Dissertação de mestrado não publicada, Universidade Federal do Rio Grande do Sul, Porto Alegre.

Katz, H., \& Greiner, C. (2005). O corpo: Pistas para estudos indisciplinares (2a ed.). São Paulo: Annablume.

Kignel, R. ( 2005). O corpo no limite da comunicação. São Paulo: Summus.

Lê Breton, D. (2007). A sociologia do corpo (S. M. S. Fuhrmann, Trad., 2a ed.). Petrópolis, RJ: Vozes. (Original publicado em 1992)

Lima, A. L. G. (1999). De como ensinar o aluno a obedecer (Um estudo dos discursos sobre a disciplina escolar entre 1944 e 1965). Dissertação de mestrado não publicada, Universidade de São Paulo, São Paulo.

Louro, G. (2007). Gênero, sexualidade e educação: Das afinidades políticas às tensões teórico-metodológicas. Educação em Revista, 46, 201-218.

Lucena, S. M. P. (2004). A auto-formação do educador no domínio do lazer: O nascer do saber-ser na prática social. Dissertação de mestrado não publicada, Universidade Federal do Rio Grande do Norte, Natal.

Marinho, H. S. (2005). Educando na vida com a dança: Corporeidade e movimento. Dissertação de mestrado não publicada, Universidade Federal de Uberlândia, Uberlândia, MG.

Merleau-Ponty, M. (1999). Fenomenologia da percepção (C. A. R. de Moura, Trad., 2a ed.). São Paulo: Martins Fontes. (Original publicado em 1945)

Mesomo, A. (2004). Educação Infantil: Indagando sobre práticas escolarizantes. Dissertação de mestrado não publicada, Universidade de São Paulo, São Paulo.

Mijolla, A. de (2005). Dicionário Internacional de Psicanálise: Conceitos, noções, biografias, obras, eventos, instituições (A. Cabral, Trad.,Vol. 1). Rio de Janeiro: Imago.
Minello, D. (2006). A dança e as práticas educativas: Uma experiência corporal reflexiva na formação de professores. Dissertação de mestrado não publicada, Universidade Federal de Santa Maria, Santa Maria, RS.

Moreira. A. F. B. (2002). Currículo, diferença cultural e diálogo. Educação e Sociedade, 23(79), 15-38. Recuperado em 27 setembro 2008, de http://www.scielo. br/pdf/es/v23n79/10847.pfd

Nascimento, M. de J. O. (1999). O corpo na ponta do lápis, na porta do palco: Uma experiência docente em educação artística. Dissertação de mestrado não publicada, Universidade Estadual de Campinas, Campinas, SP.

Nóbrega, T. P. (2005). Qual o lugar do corpo na Educação? Notas sobre o conhecimento, processos cognitivos e currículo. Educação e Sociedade, 26(91), 599-615. Recuperado em 20 setembro 2008, de http://www.cedes. unicamp.br

Nunes, A. V. (2001). Rubem Alves e a educação dos sentidos: Um estudo de seus pressupostos pedagógicos e filosóficos. Tese de doutorado não publicada, Universidade de São Paulo, São Paulo, SP.

Oliveira, E. K. (2003). O corpo e a palavra: Escrita, oralidade e performance no ensino de Língua Portuguesa. Dissertação de mestrado não publicada, Universidade de São Paulo, São Paulo.

Oliveira, L. C. F. (2007). Gênero, masculinidades plurais e identidades docentes: Um estudo das representações de homens-professores. Tese de doutorado não publicada Universidade de São Paulo, São Paulo.

Organização Mundial da Saúde (2003). Classificação Internacional de Funcionalidade, Incapacidade e Saúde (C. M. Buchalla, Trad.). São Paulo: EDUSP.

Orlandi, E. P. (2001). Discurso e texto: Formulação e circulação dos sentidos. Campinas, SP: Pontes.

Pederiva, P. L. M. (2005). O corpo no processo ensinoaprendizagem de instrumentos musicais: Percepção de professores. Dissertação de mestrado não publicada, Universidade Católica de Brasília, Brasília.

Perrenoud, P. (2002). A prática reflexiva no ofício de professor: Profissionalização e razão pedagógica (C. Schilling, Trad.). Porto Alegre: Artmed. (Original publicado em 2001)

Rocha, H. P. (2001). A higienização dos costumes: Educação escolar e saúde no projeto do Instituto de Hygiene de São Paulo (1918-1935). Tese de doutorado não publicada, Universidade de São Paulo, São Paulo.

Santos, F. A. (2003a). Corpo e pedagogia do movimento na formação do educador. Dissertação de mestrado não publicada, Universidade Federal do Rio Grande do Norte, Natal.

Santos, W. N. (2003b). Comunicação não-verbal $e$ educação: Um olhar filosófico sobre a espontaneidade da comunicação corporal como práxis pedagógica. Dissertação de mestrado não publicada, Universidade Federal da Bahia, Salvador, BA. 
Santos, M. (2004). A natureza o espaço: Técnica e tempo, razão e emoção (4a ed.). São Paulo: EDUSP.

Shimamoto, D. M. F. (2004). As representações sociais dos professores sobre humano e suas representações no ensino das ciências naturais. Tese de doutorado não publicada, Universidade Federal de São Carlos, São Carlos, SP.

Silva, T. T. da. (1999). O currículo como fetiche: A poética e a política do texto curricular. Belo Horizonte: Autêntica.

Silva, T. T. da. (2001). Os novos mapas culturais e o lugar do currículo numa paisagem pós-moderna. In A. F. B. Moreira \& T. T. de Silva (Orgs.), Territórios contestados: O currículo e os novos mapas politicos e culturais (4a ed.). Petrópolis: Vozes.

Silva, V. de L. (2004). Sentidos da profissão docente: Estudo comparado acerca dos sentidos da profissão docente do ensino primário envolvendo Santa Catarina, São Paulo e Portugal na virada do século XIX para o XX. Tese de doutorado não publicada, Universidade de São Paulo, São Paulo.

Smith, P. K. (2002). Intimidação por colegas e maneiras de evitá-la. In E. Derbardieux \& C. Blaya (Orgs.), Violência nas escolas e políticas públicas (pp. 187-205). Brasília, DF: UNESCO.

Souza, L. F. (2004). Um palco para o conto de fadas: Uma experiência teatral com crianças na educação infantil. Dissertação de mestrado não publicada, Pontificia Universidade Católica do Rio de Janeiro, Rio de Janeiro.

Tavares, S. M. G., \& Albertini, P. (2005). Moradia e corporeidade em espaços limiares: Um estudo sobre formas de subjetividade na favela. Paidéia (Ribeirão Preto), 15, 299-308. Recuperado em 11 abril 2009, de http://www.scielo.br/pdf/paideia/v15n31/17.pdf

Tibúrcio, L. K .de O. M. (2005). A poética do corpo no kit e na dança butô: Por uma educação do sensível. Tese de doutorado não publicada, Universidade Federal do Rio Grande do Norte, Natal.

Vago, T. M. (1999). Cultura escolar, cultivo dos corpos: Educação physica e gymnastica como práticas constitutivas dos corpos das crianças no ensino público primário de Belo Horizonte (1906-1920). Tese de doutorado não publicada, Universidade São Paulo, São Paulo.

Valadares, J. C. (2000). Qualidade do espaço e habitação humana. Ciência e Saúde Coletiva, 5, 83-98. Recuperado em 5 maio 2009, de http://www.scielo.br/pdf/csc/ v5n1/7081.pdf

Varela, F., Thompson, E., \& Rosch, E. (2003). A mente incorporada: Ciências cognitivas e experiência humana (M. R. S. Hofmeister, Trad.). Porto Alegre: Artmed. (Original publicado em 1991)
Marisa Helena Silva Farah é Mestre em Educação e doutoranda em Educação pelo Programa de Pós-graduação da Faculdade de Educação da Universidade de São Paulo, bolsista CAPES.
Recebido: 15/10/2008

$1^{a}$ revisão: 09/05/2009

$2^{a}$ revisão: 03/07/2009

$3^{a}$ revisão: $17 / 02 / 2010$

Aceite final: 19/03/2010 